\title{
LA POÉTICA EXTRAVAGANTE EN TEXTOS ESPAÑOLES DEL SIGLO XVI
}

LuIS AlburQuerQue García

C.S.I.C. Madrid

La inextricable relación entre Retórica y Poética es una cuestión que acompaña a todos los tratados de una y otra arte desde el mismo comienzo de su existencia.

Ya en la Poética Aristóteles remite ciertos asuntos a su tratado de Retóri$c a$, esto es, todo lo referente al tratamiento de las costumbres. Pero las remisiones de este último tratado al primero son más abundantes y todas coinciden en la necesidad de acudir a los recursos poéticos, que necesariamente coinciden con los retóricos, ya que su finalidad - dirá el Estagirita - es causar «admiración», es decir, llamar la atención!

Retórica y Poética comparten, pues, terrenos comunes que irán variando con el discurrir del tiempo ${ }^{2}$, provocando que, a lo largo de la historia, los teóricos de la materia no hayan logrado ponerse de acuerdo sobre las atribuciones que le corresponden a una y otra disciplina ${ }^{3}$.

1 Cfr. ARISTÓteles, Retórica, (ed. bilingüe de A. Tovar), Madrid, Instituto de Estudios Políticos, 1971, Libro III, 1403b-1405.

2 Un resumen histórico, breve y muy claro de las fluctuaciones entre los ámbitos propios de cada disciplina se puede encontrar en R. Barthes «L'ancienne rhétorique. Aide-mémoire», Communications, 16, 1970, pp. 172-229. Trad. cast. La antigua retórica en Investigaciones retóricas I, Barcelona, Ediciones Buenos Aires, 1982, pp. 16 y 17 (de la ed. castellana).

3 Cfr. F. LAzaro Carreter, «Introducción: La Poética» en Estudios de Poética, Madrid, Taurus, $1979^{2}$, pp. 9-30. 
Como se sabe, en el Renacimiento se produce una situación predominante de la Retórica con respecto a la Poética, lo que lleva en muchos casos a que los contenidos de esta segunda encuentren cobijo en los tratados retóricos. No quiere esto decir que en el siglo XVI -del que nos vamos a ocupar en este trabajo- no salgan a la luz tratados de poética sino que lo hacen en menor medida que los de oratoria. Estamos ante un siglo especialmente fecundo en retóricas ${ }^{4}$. La carencia de una doctrina poética en tratados independientes es algo que salta a la vista con el simple hecho de comprobar los textos poéticos que surgieron en el siglo XVI. Baste considerar que la primera poética humanista que no se reduce a mera métrica es la obra de López Pinciano5.

Lo que trataremos de hacer a lo largo de estas paginas es, después de haber rastreado con cierta minuciosidad algunos de estos tratados de retórica, analizar qué partes sirven de gozne entre una y otra disciplina, qué tipo de cuestiones sobre temas de poética aparecen en estos tratados y qué conclusiones se pueden deducir, como corolario, de estas reflexiones.

De las abundantes retóricas producidas en este siglo nos vamos a limitar en nuestra exposición a cinco tratados, coincidentes todos ellos en haber sido editados en las prensas de la Universidad de Alcalá. Por orden cronológico de publicación son los siguientes: de Antonio de Nebrija, Artis rhetoricae compendiosa coaptatio ex Aristotele, Cicerone, Quintiliano (Compluti, Guillermo de Brocar, 1515); de Miguel de Salinas, Rhetorica en lengua castellana (Compluti, Guillermo de Brocar, 1541); de Alfonso García de Matamoros De ratione dicendi libri duo (Compluti, Guillermo de Brocar, 1548); de Martín de Segura, Rhetorica institutio, in sex libros distributa (Compluti, I. Iñiguez, 1589); y por último, de Juan de Guzmán, Primera parte de la Rhetorica (Compluti, I. Iñiguez, 1589).

Aunque no lo hagan de una manera explícita, como aparece en otros tra$\operatorname{tados}^{6}$, iremos viendo cómo todos coinciden en considerar la retórica como una ciencia capaz de abarcar los distintos géneros poéticos.

4 Para hacerse una idea de este hecho basta con ver la relación de retóricas hecha por $\mathrm{V}$. ARISPE, I. CORFIS y otros, "Data format» en Dispositio, 1983, VIII, n. ${ }^{\text {os }}$ 22-23, pp. 24-64. Y también J. Rico Verdú, La Retórica española de los siglos XVI y XVII, Madrid, C.S.I.C., 1973.

5 Nos referimos a la Philosophia antigua poética, publicada en 1596. Cfr. K. KOHUT, «Retórica, poesía e historiografía en Juan Luis Vives, Sebastián Fox Morcillo y Antonio Lull» en $\mathbf{R e}$ vista de Literatura, LII, 104, p. 345.

${ }^{6} \mathrm{~K}$. KohUT en el artículo anteriormente citado dice: «dos retóricas adquieren en este contexto especial importancia: De arte dicendi libri tres de Juan Luis Vives, aparecida en 1543, y De oratione libri septem, de Antonio Lull, publicada en 1558. En ambas obras, la subordinación de la poesía y la historiografía a la retórica resulta evidente ya en la estructura externa. Ambos autores tratan en el último libro de sus respectivas obras los diferentes géneros de la oratoria, entre los cuales coinciden en contar la poesia y la historiografía.» (Op. cit., p. 346). 
Esta es la tesis que mantenía, entre otros, A. Kibedi Varga cuando decía que no debía hablarse «de la coexistencia de dos disciplinas, la Retórica y la Poética, dedicadas cada una a formas diferentes de la literatura, sino de una relación más compleja, de una relación de subordinación. la Poética clásica ha perdido toda autonomía: está profundamente "retorizada"»". Esto le lleva, páginas más adelante, a considerar la Retórica como ciencia general de la literatura, tesis que, como veremos más adelante, puede deducirse del estudio de estos tratados que ahora comentamos aquí.

Veamos. De los tres grandes géneros que Aristóteles señala en su Retórica es el demostrativo el que, a primera vista, más implicaciones tiene con la literatura. Ch. Perelman y L. Olbrechts-Tyteca en su ya clásico Tratado de la argumentación lo explican detenidamente:

«Para Aristóteles el orador se propone alcanzar, según el tipo de discurso, objetivos diferentes: en lo deliberativo, aconsejar lo útil, es decir, lo mejor; en lo judicial, defender lo justo, y en el epidíctico, que versa sobre el elogio y la censura, ocuparse sólo de lo que es bello o feo. Se trata, pues, de reconocer unos valores. Sin embargo, al faltar la noción de juicio de valor y la de intensidad de adhesion, los teóricos del discurso, siguiendo a Aristóteles, mezclan incontinente la idea de bello, objeto del discurso, equivalente, por otra parte, a la de bueno, con la idea del valor estético del propio discurso. Por eso, el género epidíctico parecia depender más de la literatura que de la argumentacion» ${ }^{8}$.

En suma, que la confusión entre el fin y los medios propios de este género, es lo que ha dado lugar a una relación tan estrecha entre el discurso demostrativo y el discurso propiamente literario.

Esta confusión está presente desde muy temprano, aunque no es compartida por nuestros autores. Jorge de Trebisonda en su tratado de retórica ${ }^{9}$ considera este género como fuera de toda causa debido a que - según su opiniónla alabanza y la vituperación, objetos propios del discurso epidíctico, no entrañan ningún mecanismo estrictamente retórico.

7 Rhétorique et littérature, Paris, Larousse, 1970, p. 25. Apud F. Lázaro Carreter, op. cit., p. 16.

8 Tratado de la argumentación. La nueva retórica, Madrid, Gredos, 1989, p. 96.

9 Opus absolutissimum rhetoricorum (con anotaciones de Herrera), Compluti, Arnaldo Guillermo de Brocar, 1511. 
Nebrija en su Artis rhetoricae dedica todo el capitulo XXII a este género. Para él, sin embargo, no ofrece ninguna duda considerarlo como un género de la causa.

Pero es García Matamoros quien afirma rotundamente que se trata de un género con toda propiedad («est verum genus causae») porque - dirá«quod in foro facit adversarius, id in concione praestat tacita dissentientes cogitation 10 .

Miguel de Salinas en su Rhetorica en lengua castellana argumenta en la misma linea que los dos autores anteriores. Recogemos in extenso, por ser muy significativas, sus palabras:

«en el demostratiuo dizen algunos rhetoricos y especialmente Trapezuncio lo affirma que no ay estado y que quando pareciere auer lo ya dexa de ser demonstratiuo, pero agora allegandonos a los mas autores o por enseñar lo mas claro dexando las razones que en contrario Trapezuncio pone, diremos que tiene estado, como qualquier de otros generos, aunque no tan a la clara, y sera presuponiendo nosotros mismos la contradicion de lo que intentamos demostrar o alabar y como si nos estuuiessen diziendo que mentimos assi ponemos nuestras fuerças a satisfazer las dudas que de las contradiciones salen que seran en lugar de estados. $Y$ aunque aya algunas proposiciones tan aueriguadas que no tienen contradicion como dezir que dios es bueno y misericordioso, porque el que lo negasse seria loco, pero aun en estas si se han de probar y enseñar complidamente se deuen presuponer contradiciones y sacar estado al qual se apliquen las razones y argumentos de manera que en qualquier genero de causa que sea auemos de presuponer que ay estado» 11 .

Parece claro para estos autores que las nociones de juicio de valor y de intensidad de la adhesión (características de todo discurso persuasivo) no se encuentran al margen de los discursos demostrativos (ni de ningún discurso en sentido amplio). Podemos deducir, por tanto, a la vista de estos textos, que cualquier género, literario o no, dispara un proceso comunicativo del que puede ser modelo esquemático la comunicación judicial. La búsqueda del

10 «Lo que el adversario hace en el foro, esto otorga el pensamiento no pronunciado a los que disienten en la asamblea» (De ratione dicendi, cap. IV, fol. XV).

"Op. cit., cap. 1 XVIII, fols. XXXIr. y XXXIv. 
status $^{12}$ es algo que subyace aunque sea de manera inconsciente, en todo tipo de discurso. Aun en los géneros literarios (los que más se aproximan al género epidíctico), aparte de la finalidad primordial de elogio y censura, se descubren otras no menos importantes relacionadas con la adhesión a ciertos valores (pensamos, sin ir más lejos, en el ejemplo referido por Salinas acerca de la bondad y misericordia divinas ${ }^{13}$ ).

Como sabemos, el carácter dialéctico del proceso retórico exigía que cada uno de los litigantes representara la parte jurídicamente superior y la parte jurídicamente inferior, respectivamente. Y este grado de representabilidad o de defendibilidad procedente del modelo judicial sirvió de dechado para los otros géneros. Se distinguen en los tratados que comentamos, básicamente, cuatro géneros de defendibilidad de una causa, procedentes de Cicerón y Quintiliano. Si la causa que se defiende es algo que responde total o plenamente al sentimiento jurídico o a la conciencia general de los valores del público se denominará género honesto (honestum genus); si la causa que se defiende choca contra el sentimiento jurídico o la conciencia de los valores y verdades del público estamos ante un género torpe (turpe genus); si una causa provoca en el sentimiento jurídico, o en la conciencia general de los hablantes, un serio

12 Podríamos definir el «estado» (status), término jurídico, como «situación» o momento de la acción que suscita mayor interés. No es difícil, por tanto, relacionar las «situaciones jurídicas» con otro tipo de «situaciones» transferibles a la vida no judicial. Este marco del foro sirve de plantilla para todos aquellos discursos en los que se pretende influir sobre el oyente (auditorio) que, como acabamos de ver en los tratados objeto de nuestro estudio, son prácticamente todos 0 , al menos, los demostrativos (más próximos a los literarios) no estarían exentos de esta carga argumentativa. Así por ejemplo en el drama, el espectador, estando realmente presente en esa situación, marca las pautas del enfoque de una obra, bien sea para seguir sus gustos, bien sea para cambiarlos, pero siempre se tendrá en cuenta que la obra se representa pensando en el como árbitro que delibera lo que se está representando en su presencia.

13 Tienen especial interés estas observaciones de SALINAS porque lo que en el fondo se debate son temas tan actuales como el papel que en la sociedad tiene la educación. Nos parece muy ilustrativo en este sentido lo que dicen Ch. Perelman y L. Olbrechts-Tyteca en su libro anteriormente citado: \&Los discursos epidícticos tienen como finalidad aumentar la intensidad de adhesión a los valores comunes del auditorio y del orador[...] Lo que esta idea pone muy bien de manifiesto es precisamente el papel de los discursos epidícticos; apelaciones a los valores comunes, no discutidos aunque no formulados, y por alguien que tiene cualidades para hacerlo; fortalecimiento, por consiguiente, de la adhesión a estos valores con vistas a posibles acciones ulteriores.[...] El discurso educativo, igual que el epidíctico, tiende, no a revalorizar al orador, sino a crear cierta disposición en los oyentes. Contrariamente a los géneros deliberativo y judicial, los cuales se proponen obtener una decisión de acción, el epidíctico, como el discurso educativo, crean una simple disposición a la acción [...] El discurso epidíctico -y cualquier educaciónpersigue menos un cambio en las creencias que una argumentación de la adhesión a lo que ya está admitido." (Op. cit., pp. 102-104). 
problema respecto a su defendibilidad, nos hallamos ante un género dudoso (dubium genus); por último, si la causa representa para el sentimiento jurídico, o la conciencia común de los hablantes, un proceso de escasa importancia y sin interés, se le llamará género humilde (humile genus) ${ }^{14}$.

Este humile genus dará pie a que García Matamoros en su De ratione dicendi introduzca unos comentarios que se corresponden más apropiadamente con los discursos literarios:

«Porque (como dice Fabio) no pocos medicos hicieron alabanzas a cada uno de los alimentos; e incluso podemos encontrar alabanzas al sueño profundo. Es más, no pocos oradores, de la misma manera, unas veces para ejercitar la elocuencia, otras para demostrar su ingenio, llenaron de grandes alabanzas las cosas que por si mismas son torpes y deshonestas» ${ }^{15}$.

Más adelante da cuenta el propio Matamoros de aquellos textos antiguos y modernos que han alabado cosas intrascendentes como La mosca de Luciano, La fiebre cuartana de Pavorino y, más recientemente, La locura de Erasmo, además de la alabanza abundante y con estilo que Pedro Mexía ha hecho del asno ${ }^{16}$.

Este género o, más bien subgénero, que Matamoros llama «torpe» y se identifica con el contenido del que más arriba hemos denominado «humilde», es ejemplificado por este autor con textos de Tito Livio.

Esta aplicación del género «humilde» a textos narrativos (aplicación que también aparece en otros autores como Juan de Guzmán ${ }^{17}$ ) es un hecho más que confirma el desbordamiento de la teoría retórica hacia géneros poéticos.

14 Cfr. H. Lausberg, Manual de Retórica literaria, Madrid, Gredos, 1966-1968, 3 vols., pp. 112-117.

15 «Nam (ut refert Fabius) singulos cibos medici nonnulli laudarunt, \& somni aeditae sunt laudes. Quin quae per se etiam turpia, \& inhonesta sunt, aut exercendae eloquentiae, aut ostentandi ingenii gratia, non ita pauci oratores magnis laudibus provexerunt». («liber primus», cap. V, fol. XI).

16 «Sic muscam Lucianus, Phavorinus quartanam febrim, Erasmus nuper moriam, \& Petrus messia vir variae, reconditae atque doctrinae, certissimum nostri seculi ornamentum, \& decus copiose, \& ornate asinum commendavit” (lbid.).

17 *El genero baxo es, alabar las cosas que no tienen estima del modo que Luciano alabo la moxca, Erasmo el escaravajo, y Pedro Mexia el asnow (Primera parte de la retorica, fol. 20r.). 
Si del terreno de la preceptiva pasamos al de la práctica, o sea, al de las obras literarias concretas, nos encontramos con que muchos estudiosos han descubierto aquí un campo especialmente fértil de conexión de la teoría con la práctica literaria. Así, muchos ven en la novela picaresca un modelo de cómo se ha conseguido aplicar este genus humile a la literatura de nuestro Siglo de Oro ${ }^{18}$.

La aplicación de los preceptos retóricos a textos escritos ha encontrado un éxito insospechado dentro de un género (especie) que había permanecido estéril desde su primera aparición dentro del género judicial ${ }^{19}$.

No es necesario insistir en el hecho de que el género demostrativo es el que, potencialmente, ofrece más posibilidades que ningún otro para un aprovechamiento más fecundo dentro del campo literario. Pero es que, además, no nos es ajeno que el género judicial en el siglo XVI apenas tiene uso; la jurisprudencia ha sustituido a la argumentación retórica, remitiendo su interpretación a las leyes y fórmulas que se han ido acuñando a lo largo de los siglos. Apenas tiene cabida la retórica en la práctica judicial. Esta afirmación es compartida por la gran mayoría de los tratadistas.

Para Nebrija la práctica judicial casi no tiene uso ni para los que viven (como es su caso) bajo jurisdicción pontificia, ni para los sometidos a la jurisdicción del reino ${ }^{20}$. Por todas estas razones Nebrija prescinde en su compendio de este género, de manera que sólo tratará del demostrativo y del deliberativo, únicos géneros de verdadero uso en su época:

«...de modo que no hay nada de qué admirarse en el hecho de que el arte retórica haya llegado casi a su destrucción y que aparezca solamente en los predicadores, pues como dice Aristóteles, las artes terminan por pe-

18 Dice H. Lausberg al respecto: *La defensa de un proceso de mínima cuantía (genus humile) no vale la pena, pues la causa es también para el contrario un proceso de mínima cuantía. La caracterización del proceso de mínima cuantía está orientada sociológicamente («Pauper vestimenta vendebat...n); la defensa de un pleito de esta categoría no compensa al orador ni siquiera en el orden crematístico. Sin embargo, el genus humile ha encontrado realizaciones en el campo literario: algunos literatos que han medido sus fuerzas con el difícil genus turpe, se han sentido atraídos por la especial dificultad del genus humile. Y han logrado demostrar que incluso al banal circulo de personas y problemas del mundo de los pobres y mendigos (novela picaresca) se le puede arrancar un interes humano y literario. - Propiamente, también la comedia pertenece al genus humile» (Op. cit., p. 115).

19 Vid. E. ARTAZA, El "ars narrandi" en el siglo XVI español. Teoría y práctica, Bilbao, Universidad de Deusto, 1989, pp. 277 y sgtes. Vid. también F. Rıco, Problemas del "Lazarillo", Madrid, Cátedra, 1988, cap. VI.

20 Cfr. cap. XXIV de su tratado. 
recer si no se fija en los trabajos y en las labores penosas más que en lo que de ganancia (provecho) ha de venir de alli. Así, omitida esta parte, nos dirigimos a otra.... ${ }^{21}$.

Miguel de Salinas sitúa el género judicial como mero apéndice de su tratado. Matamoros subraya estas mismas opiniones y añade que, históricamente, la tal mencionada decadencia es un proceso que se remonta a tiempos ya muy lejanos.

Juan de Guzmán aporta la idea de que este género está incluido también en el deliberativo cuando éste confuta los vicios y cosas que nos dañan.

Esta reducción del panorama retórico no implica necesariamente que la materia de la retórica haya estrechado sus intereses. Todo lo contrario. Cuando llegamos al apartado en el que se tratan cuestiones relativas a la materia «propia del arte» estos autores extienden su dominio indefinidamente. Ciertamente, esta universalización de la materia retórica no es una innovación de estos tratados puesto que en la Institutio Oratoria de Quintiliano podemos leer que «la Retórica no está sólo en los juicios y en las asambleas sino también en los asuntos privados y domésticos» ${ }^{22}$.

Nebrija, Matamoros, Salinas, Segura y Guzmán se hacen partícipes de la misma idea, aunque expresada con matices distintos.

Si cualquier tema es objeto de consideración por parte de la retórica la reivindicación de unos géneros concretos no parece ya pertinente. De hecho, los discursos deliberativos o asamblearios han pasado a ocupar otro escenario completamente distinto y con una temática muy diversa; nos referimos a la retórica sagrada que dio lugar a abundantes tratados dedicados exclusivamente al arte de la predicación.

Nebrija, al comienzo de sus comentarios sobre el género deliberativo pone especial hincapié en señalar que la persuasión y la disuasión constituyen las dos posibilidades de este discurso, el cual no se refiere sólo a la política sino a otras muchas cosas ${ }^{23}$.

21 *... ut nihil mirandum sit: cur ars rhetorica in interitum prope modum sit redacta: atque in solis concionatoribus reperiatur. Nam quemadmodum ait Aristoteles interirent utique artes: si illarum operibus plus impensarum \& laboris insumatur: quam inde sit emolumenti perventurum. Quare omissa hac parte nos ad alia properemus...” (Op. cit., cap. XXIV, fol. 25v.).

22 Institutio Oratoria (ed. bilinglie latín-inglés de H.E. Butler), Londres, Cambridge, Mass., Loeb Classical Library, 1963, 4 vols, II, XXI, 4, p. 356.

23 «Deliberativum genus quod duas habere species dictum est suasionem uidelicet ac dissuasionem: non solum in reipublica administratione, uerum etiam in aliis quodque rebus uersaturn.(Op. cit., cap. XXIII, fol. 23r.). Como es el caso de la literatura, en la que probablemente esté 
El proceso de comunicación en el que se basa el organismo retórico es tenido en cuenta por Nebrija con todo rigor: quién o quiénes deliberan, qué es sobre lo que se delibera y quién es el sujeto activo de la persuasión ${ }^{24}$.

Es claro que este esquema procedente del discurso deliberativo está presente en la Retórica literaria.

Fija más adelante Nebrija su atención en la instancia del emisor ${ }^{25}$ en la comunicación persuasiva. El estatuto del orador condiciona, lógicamente, el mensaje proferido. No es indiferente quién sea el emisor concreto de un determinado discurso; lo mismo que no es de menor trascendencia el contexto en el que se desarrolla la comunicación, ni el estatuto del receptor o receptores ${ }^{26}$.

Como podemos suponer estas consideraciones, aunque no sustanciales, gozan de una enorme importancia en la comunicación literaria en la que el estatuto de autor permite que se califique de «literario» el texto puesto en circulación. Una cuestión, pues, de pragmática literaria es básicamente algo propio de retórica. Unas lineas más adelante Nebrija apostilla lo que venimos subrayando: «Nam quae in aliis libertas est, in aliis licentia vocatur».

Estos tratados - las referencias de Nebrija-Quintiliano son muy similares en lo esencial a las otras preceptivas - apuntan aspectos de actualidad que, evidentemente, carecen de elaboración y de instrumentos adecuados. La noción implícita de estatuto es lo que hoy denominaríamos «argumento de autoridad».

El último apartado de este capitulo del tratado nebrisense se refiere a la «prosopopeya» y no como figura retórica sino como ejercicio de adecuación de registro. Explícitamente se llama la atención sobre su utilidad no sólo para oradores sino para poetas e historiadores:

«por tanto me parecen, con mucho, dificilísimas, las prosopopeyas, en las que al restante trabajo de la persuasión se añade también la dificultad de la persona. Pues el mismo tema deberá persuadir de una manera César, de otra manera Catón, de otra manera Cicerón. Este ejercicio es verdaderamente utilísimo porque responde a un doble esfuerzo, que confirma mucho

pensando Nebrija. Sobre este hecho ha llamado recientemente la atención M.A. Garrido Gallardo: «...la retórica literaria no deja de ser persuasiva. La distinción entre llamar la atención («retórica literaria»)/conseguir la adhesión («retórica persuasiva») es un espejismo. Las «figuras» no tienen como misión única (ni, a veces, principal) llamar la atención».(«Homo rhetoricus» en A.E.S. (ed.), Investigaciones Semióticas III, 1, Madrid, UNED, 1990, p. 24).

24 Ibidem.

25 lbidem, fol. 25r.

26 Ibidem, fol. $24 \mathrm{v}$. 
a los poetas, también a los futuros escritores de historia; y resulta muy necesaria para los oradores" ${ }^{27}$.

Al final se añade que el discurso ha de acomodarse no sólo al que lo pronuncia sino al tema que se expone. Están aquí presentes, pues, los elementos básicos para la congruencia textual: la adecuación de mensaje, tema y sujeto ${ }^{28}$.

Hemos tomado a Nebrija como principal hilo conductor para el desarrollo del discurso deliberativo. De Salinas diremos que los planteamientos son muy similares no destacando ninguna aportación singular distinta de las apuntadas por Nebrija. Para corroborarlo recogemos lo que dice con respecto a la importancia, ya comentada, del receptor en la comunicación retórica: «Ay differencia de hablar delante doctos o simples, delante de personas de manera o gente que no lo es, padre carnal o espiritual, superior o ygual en edad o dignidad con otras circunstancias» ${ }^{29}$.

García Matamoros en su De ratione dicendi aporta a todo lo dicho hasta ahora en el género deliberativo ejemplos concretos procedentes de la literatura. Así, Tito Livio se convierte para este autor en una referencia básica.

Martín de Segura hace especial hincapié en la necesidad del orador de «excitar» e «inflamar» (mouere) los ánimos de los oyentes. Se trata, por tanto, de convencer al auditorio pero también de disponer su ánimo para la acción ${ }^{30}$.

Juan de Guzmán al considerar que este género engloba a los restantes ${ }^{31}$, está planteando el verdadero tema de fondo: la existencia de un discurso único capaz de amoldarse a las necesidades de cada momento y capaz de englobar todos los discursos posibles. Que esta deducción no es gratuita se comprueba cuando observamos que las recomendaciones que Guzmán hace a lo largo de

27 «Ideoque longe mihi uidentur difficillimae prosopopoeiae, in quibus ad reliquum suasoriae laborem accedit et personae difficultas. Namque illud idem aliter Caesar, aliter Cato, aliter Cicero suadere debebit. Utilissima uero haec exercitatio uel quod duplicis est operis, uel quod poetis, uel quod historiarum quoque futuris scriptoribus plurimum confert \& oratoribus necessaria.» (Op. cit., fol. 25r.).

28 Quede enunciada sin más la vinculación entre estos planteamientos y la actual teoría de la pragmática de la comunicación .

29 Op. cit., fol. XXXIIIv.

30 *Genus est, quod maxime vestros animos excitare, atque inflamare debet, in quo agitur populi Romani glorian. (Rhetorica institutio, in sex libros distributa, fol. 14v.).

31 \&Y aunque no cumplidamente, digo que abraça al judicial, quando confutamos los vicios y cosas que nos dañan, y abraça al demonstrativo, quando ensalçamos las cosas de virtud, exortando al auditorio para que las abraçe.» (Primera parte de la retórica, fol. 18v.). 
su tratado se refieren tanto a la retórica como a la poética, como veremos inmediatamente ${ }^{32}$.

De los géneros aristotélicos pasamos ahora a considerar el apartado de la «narración» (narratio). Seguiremos más de cerca, en esta ocasión, la doctrina expuesta por Juan de Guzmán.

En el «combite quinto» se nos presentan las que él considera seis «partes de la oración»:

1. Persona faciens (o persona que hace).

2. Res gesta (o cosa hecha).

3. Tempus circa quod (o tiempo en que se haze una cosa).

4. Locus in quo transfacta (o lugar donde fue hecha).

5. Modo in quo pacto (o modo o manera como se hizo) y,

6. Causa propter quam (o causa porque se hizo) ${ }^{33}$.

Ciertamente estos «lugares» no son una creación del autor (recordemos que se trata de una retórica en lengua castellana) ya que mantiene hasta los nombres latinos. La novedad, una vez más, es el consejo que nos transmite el autor de la utilidad de estas «partes de la oración» sobre todo para la «narración histórica» y para la «narración de los poetas», lo que se ejemplifica con un texto de la Eneida de Virgilio.

Este apartado de la «narración» se cierra con consideración de que «estas narraciones lleuaran unas vezes las conjunciones ordinarias, segun se vee en esta» (se refiere a las estrofas recogidas de la Eneida).

Estas apostillas entresacadas de la retórica de Guzmán son una manifestación palmaria de que estamos ante una preceptiva con abundantes implicaciones retórico-poéticas. La relación de estos textos, por ejemplo, con planteamientos de la Lingüística del Texto no es gratuita. Estas consideraciones se pueden aplicar sin ninguna violencia a la «narratología», pues la enumeración de las mencionadas seis partes de la oración no es sino una búsqueda de las «leyes universales» de todo texto, asunto que ha suscitado en repetidas ocasiones la atención de los estudiosos de la teoría del relato ${ }^{34}$.

32 Esta tesis del «discurso único» en algunas de las retóricas del quinientos es mantenida por K. KOHUT en el artículo ya citado. (Op. cit., p. 345).

${ }^{33}$ Op. cit., fol. 106r y 106v.

34 Cfr. W. Propp, Morfología del cuento, Madrid, Fundamentos, 1971 y C. BRÉmond, Logique du récit, Paris, Seuil, 1973. 
Si de la «narración» pasamos a la «argumentación» nos encontramos con algunos puntos de no poco interés. De García Matamoros tomamos ahora la cita a propósito de los «lugares comunes»:

«Así pues, pueden servir de ayuda en esta parte a nuestro propósito una especie de índices de lugares comunes como los que hemos redactado que simultáneamente sirvan de ejemplo y modelo y que alberguen ordenadamente pulcras y selectas sentencias de autores, lo que facilita su uso a primera vista y rápidamente. Pues también es propio del arte disponer las expresiones por orden alfabético, ya que las que se presentan de inmediato y acuden primeramente a la mente no se han de incluir sin más en el elenco ordenado, sino las que fueren comunes y de máxima generalidad y que contengan doctrina. Como son los nombres de las virtudes, los vicios, las artes, las diciplinas, los menesteres ${ }^{35}$.

Curiosamente, estos «lugares comunes» tienen mayor aplicación desde un punto de vista "artístico» que desde uno meramente argumentativo. Estamos ante la imitatio, imprescindible, como se sabe, en la doctrina poética.

Juan de Guzmán hace aquí una observación de cierta importancia aunque no es el único ni el primero en ponderarlo. Se refiere al interés de tener presente en todo discurso los efectos que produce en el interlocutor la enunciación discursiva y no solamente la coherencia interna del enunciado ${ }^{36}$. Se trata de tener en cuenta el carácter dialéctico del discurso y sus efectos pero sin olvidar el papel clave que juega en todo discurso la propia enunciación. Sin duda, aunque no lo haga explícito está pensando en la doctrina de la "catarsis» cuyas implicaciones son, evidentemente, poéticas.

Salinas se refiere a este mismo problema en su Rhetorica en lengua castellana, encuadrándolo en el apartado no de la argumentación sino de la «pe-

35 «Itaque iuuandi sunt hac etiam parte industria nostra ii, in quorum gratiam haec conscribimus, simulque exhortandi, monendique videntur, tum locorum communium indices , \& quam primum, \& quam diligentissime faciant, in quos pulchras, selectasque authorum sententias ordinate conferant. Sed artis quoque est, per ordinem alphabeti dictiones disponere. Nam obuiae quaeque \& quae primum in mentem uenerint, non statim erunt in ordinem, redigendae, sed quae maxime communes \& generales fuerint, \& quae doctrinam contineant. Ut sunt nomina virtutum, vitiorum artium, disciplinarum, officiorum». (Op. cit., cap. IX, «liber secundus», fols. LXIIv. y LXIIIr.).

${ }^{36}$ Op. cit., fols. $127 \mathrm{v} .-128 \mathrm{r}$. 
roración» y, más concretamente, de los «afectos». Pondera el carácter plástico de las descripciones de la siguiente manera:

«No ay quien no se turbe si viere a uno mudado el gesto, la espada en la mano, dando bozes y bramando contra otro que está temblando y sin ayuda, $y$ le da de cuchilladas hasta que le derriba, y herido, con muchos gemidos se muere; mas que si oymos aver le muerto muy cruelmente. $Y$ por esto es muy gran ventaja quando los que escriuen ponen la cosa con tanta euidencia, que realmente parezca a los oydores que la veen ${ }^{37}$.

Salinas está defendiendo también el recurso a los efectos en el discurso oratorio aludiendo de nuevo a su carácter «patético».

La separación entre Retórica y Poética es mucho menos nítida que en el tratado del Estagirita en el que, como recordamos, el acento se colocaba sobre todo en el efecto proveniente de los razonamientos y de las pruebas (la retórica -dirá Aristóteles- es «antistofra» de la dialéctica). De todas maneras, al final del capítulo, Salinas insiste en que los procedimientos para mover los afectos han de ser ante todo discursivos y textuales y no derivados de la propia emotividad del orador: «assi el que ha de amonestar a otros le conuiene reprimir qualquier passion que le puede estoruar a dezir lo necessario: como son lagrimas y solloços o otra demasiada turbacion» ${ }^{38}$.

Salinas está pensando en la oratoria sagrada cuando insiste en que el orador procure suscitar emociones sin emocionarse, y que procure guardar la compostura el predicador («ni tampoco esta bien a los predicadores y hombres graues mouer estas passiones con gestos y meneos extremados del cuerpo como a los truhanes y hombres que no tienen mucha verguença» ${ }^{39}$ ) como ha sido señalado por la doctrina tradicional desde los padres hasta nuestros días.

En este mismo apartado de los afectos Alfonso García Matamoros destaca de nuevo por su reiterada mención de la fuente virgiliana, lo que pone de relieve, una vez más, la identidad de procedimientos del lenguaje afectivo en el discurso poético y en el discurso oratorio ${ }^{40}$.

37 Rhetorica en lengua castellana, fol. LVIIIr.

38 Ibidem, fol. LVIIIv.

39 Op. cit. fol. LIXr.

40 No llama la atención, pues, que la estilística de principios del siglo XX que sustituyó a la retórica, se ocupara de los «valores afectivos» del lenguaje. Es este un tema de trascendental importancia que ha ocupado la atención de la teóricos del arte como punto crucial para la interpretación de la expresión artística. Véase al respecto el esclarecedor artículo de E. GoMBRICH, «Cuatro teorías sobre la expresión artística», Atlantida, 9, Enero/Marzo 1992, pp. 4-22. 
No deja de hacer alusión también a la comedia clásica como ejemplo de movimiento de afectos. Es ya, por tanto, doctrina común en estos tratados, como vimos más arriba, que una dimensión básica de la Poética (su carácter «patético») es, desde luego, fundamental en la retórica.

Martín de Segura destaca en el breve apartado que dedica a la «peroración» la importancia expresiva de que goza el material lingüístico propiamente dicho:

"[La amplificación se logrará] si las palabras son sonoras, con letras de fuerza y bondad natural: asf, las vocales "o", "a", como Romanos; " $n$ ", " $t$ ", iunctae, como furentem audacia, " $\mathrm{r}$ ", como rumpo, o unida a otra consonante, como flagrare coepit amenta, perfregit, prostrauit, omnia cupiditate ac furore. Sean las palabras plenas, es decir, que consten de muchas sílabas y llenen bien la tensión de la pronunciación: cum equites Romani relegarentur. qui tyranni nominabuntur? (...) ${ }^{41}$.

Resaltamos la alusión latente de Segura en este texto al valor simbólico de los sonidos, tema que ha sido una constante en la Poética universal ${ }^{42}$.

Todo lo traído a colación hasta este momento se refiere a partes de la retórica no relacionadas directamente con la «elocución» (elocutio) o teoría de la expresión. Luego no es necesario insistir una vez más, consideradas estas apostillas a los tratados comentados, en la falta de rigor de determinados planteamientos que postularon un resurgimiento de la retórica atendiendo únicamente al carácter elocutivo de esta arte ${ }^{43}$.

41 «Si verba sint sonantia, quorum litterae habeant vim et bonitatem natiuam. Eius modi sunt, "a", "o", vocales, ut Romanos; "nt", iunctae, ut furentem audacia, " $r$ ", ut rumpo, vel alteri consonanti adiuncta, sic, flagrare coepit amenta; perfregit, prostrauit omnia cupiditate ac furore; verba etiam sint plena, id est, quae multis syllabis constent, et compleant pronuntiandi contentionem; sic, cum equites Romani relegarentur, qui tyranni nominabuntur? (...)». (Rhetorica Institutio, uliber primus», fols. 21r.-21v.).

42 Vid. a este prop6sito el reciente libro de M.J. VeGA, El secreto artificio. Maronolatria y tradición pontoniana en la poética del Renacimiento, Madrid, C.S.I.C.-Universidad de Extremadura, 1992.

43 Nos parecen oportunas a este propósito las palabras de M.A. GARRIDO Gallardo en el artículo anteriormente citado: *Sin duda, nadie recuerda ya hoy que hace unos años había quien cara en la trampa de considerar que posé́a la clave indiscutible de la literariedad. Aquella poéticaretórica que no tenfa en cuenta al principio de distintividad (no todos los textos «figurados» son literarios) ni de exhaustividad (no todos los textos literarios son figurados)». (Op. cit., p. 24). 
La evidencia de que la teoría de los «tropos» y «figuras» está en permanente contacto con la poética, nos lleva a que prescindamos de toda referencia en este apartado, excepto la de recordar que Nebrija omite esta doctrina en su tratado por considerar que es más propia de la gramática. Se trata del primer intento de una teoría de la lengua literaria. Se pone de manifiesto, una vez más, que las fronteras entre la lingüística y la literatura y entre la lingüística y la oratoria no son tan fáciles de delimitar.

En resumen, un estudio detenido de algunos aspectos y cuestiones que atañen a la Retórica del siglo XVI nos confirma, en primer lugar, que esta disciplina no es separable de la poética y que, aunque sepamos que en este siglo se distinguían ambos términos está claro que, al menos, no lo hacían de manera unívoca. En segundo lugar que el discurso epidíctico literario no está exento de los dispositivos propios de la argumentación, como se ha podido colegir de las consideraciones de estos tratados acerca del discurso demostrativo.

A esto añadiremos otra consideración. Si el armazón doctrinal de la Retórica parece que contiene virtualmente todas las posibilidades de análisis del discurso verbal (y no sólo literario) tal vez no sea exagerado, a la vista de estos tratados del siglo XVI, que la «vieja» retórica clásica sea considerada, así se viene proponiendo desde hace más de una década ${ }^{44}$, como ciencia general del discurso.

44 Vid., por ejemplo, A. GARCIA BERRIO, «Il ruolo della retorica nell'analisi-interpretazione dei testi letterari», Versus, 1983, pp. 99-154. Versión cast.: «Retórica como ciencia de la expresividad (Presupuestos para una Retórica general)», E.L.U.A., 2, 1984, pp. 7-59. Cfr. también M.A. GaRRIDo Gallardo, op. cit. y también «De que el mono desciende del hombre. Perspectivas actuales de la semiótica» en Introducción a la semiótica. Actas del curso de «Introducción a la semiótica», Granada, Instituto de Estudios Almerienses, Departamento de Arte y Literatura, 1992, pp. 15-30. 